\title{
Improving Mental Health Outcomes for Black and Minority Ethnic Communities: A Quantitative Study into Perception of Control
}

\author{
Dr Stephen Joseph ${ }^{*}$ and Professor Frank Keating \\ Royal Holloway University of London \\ * Corresponding author email: stephenjoseph19@gmail.com \\ Received: 08 December 2020 / Revised: 27 January 2021 / Accepted: 11 March 2021 / Published: 22 March 2021

\begin{abstract}
Background: Although the disparities in mental health outcomes for ethnic minorities in the United Kingdom are well-documented, little is known about the role perception of control plays in the experiences of service users and its role in perpetuating or improving health inequalities. This quantitative methods study investigated the perspectives of the members of these communities from the Locus of Control domain.

Methods: A small-scale survey $(\mathrm{N}=50)$, applied a purposive sampling method to recruit mental health service users of African and Caribbean origin from a South London Borough to complete two structured questionnaires. Data were analysed using SPSS in the examination of the scores, various demographic variables, linear relationships, and other reliability tests.

Results: Key findings indicate a moderate to high externality in LOC scores for participants, in general and mental health milieus, with some remarkable differences in ethnicity, gender, and age.

Conclusion: The results present some implications and opportunities for mental health services, policy, and professionals in engaging with clients from this target group towards addressing the inequality of outcomes.
\end{abstract}

Keywords: Black and Minority Ethnic; Locus of Control, Mental health

\section{Introduction}

There is an over representation of the Black and Minority Ethnic (BME) communities in psychiatric health care settings in the United Kingdom [1]. The groups' experience with mental health services has also recorded a high dissatisfaction rate, including perceived adverse stereotypes, such as being "Black and dangerous", and inequality and more complex pathways to care [2-9], sometimes culminating in avoidance of and resistance to Mental Health Services (MHS). This issue was highlighted in the "breaking the circles of fear' report by Keating et al [10], which found that members from this group experienced fear of mental health services, police involvement in entry to services, stigma, admission by detention via the use of the Mental Health Act (MHA), [11-12], coercive practices, late entry to services along with other challenges, combine to promote the circles of fear, and less focus on recovery approaches. Furthermore, fear, mistrust and averseness to engagement has also characterised the BME response to mental health services [13-15]. Mental health service users are impacted by various factors such as social, financial, and economic stressors which contribute to the development of their illness $[8,16,17]$. These inequalities in mental health outcomes have also been accentuated by the current COVID-19 pandemic $[18,19]$, which started in 2020 as it has also been observed that BME populations experience higher levels of negative mental health outcomes in comparison to the general population in the United Kingdom, thereby worsening the inequalities [19]. It has also been observed that "social disadvantages including unemployment; lone parent status; lower social class; low perceived social support; poverty..." and other issues contribute to the development of psychosis [17: 1547]; and that strong connections exist "between deprivation, ethnicity, and mental illness" [20: 40]. Furthermore, an integral part of considering the psychosocial aspects of mental health service users also 
Improving Mental Health Outcomes for Black and Minority Ethnic Communities: A Quantitative Study into Perception of Control

includes the need to explore the link between their cultures and their perception of control in their life experiences [25]; thereby raising the desirability of investigating the concept of locus of control from the perspectives of the ethnic minorities in the United Kingdom.

\section{Locus of Control, general and mental health}

Locus of Control (LOC) is rooted in psychology and social learning theories [22-23] and is based on how individuals conduct subjective appraisal of the factors that are responsible for the actions and occurrences in their lives. It refers to the level to which individuals consider that they can influence their environment, and the extent to which they consider their experiences are dictated by forces outside of themselves, or circumstances beyond their control, including actions of other people and chance occurrences [24-26]. LOC can be either internal or external; internal LOC refers to a belief by an individual that events, occurrences, and outcomes are decided by their own actions, while someone with an external LOC considers that their fortunes or otherwise are dictated by forces outside themselves, and for which they have little control or influence $[21,24,26]$. This implies that they perceive that their actions would bear little or no relevance or make a difference to whatever happens to them. Social learning theorists including Rotter, [27, 30], assert that the way people perceive their sense of judgement over control in their lives are not inborn but emanate from their individual experiences over time including effects from the society, which tend to strengthen their perception [28].

Various studies have explored the relationship between LOC and health in general, as well as specific areas of health seeking behaviours [25-29]. Earlier studies in this area using the foundational model [29,30], posit that internals are those who have the perception of control over their health while externals are individuals who believe that their health is not within their control [31]. It was also generally concluded in earlier studies that individuals located within the internal LOC spectrum are likely to participate in conducts and behaviours that will promote their health $[21,25]$. Conversely, individuals who are of the external LOC orientation are likely to indulge more in behaviours which would not promote their health. Other earlier authors $[32,33]$ assert that the differences in health behaviour between the internals and externals will result in better health outcomes for the internals than the externals. It was also found that the LOC orientation of individuals will also dictate the extent to which their health behaviour is influenced by the social environment and the influence of family and friends [34]. Strickland, [35] suggests that individuals with internal LOC are less likely to submit to pressure from others to undertake poor health habits, as they are more likely to draw their own individual conclusion when confronted by opposing suggestions from external sources that they may find to be challenging their views and health related behaviours [29]. In comparison however, external LOC oriented persons may be more susceptible to the non-health promoting behaviour in their environment, either directly or indirectly, when exposed to similar situations [29]; they may also be prone to be passive to health promoting behaviour [34]. One area that is seldom explored in relation to powerful others, in the form of the medical professionals' impact on external LOC orientation was highlighted in a study [36] that assessed Health Locus of Control of 11,600 participants in Wales. It confirmed findings of previous studies that internal LOC motivated positive health behaviour, and that a perception that one's health was controlled by fate and chance motivated poor health behaviour [37-39]. It has also been found however, that individuals who have a strong belief in the role of powerful others are likely to engage in lower levels of positive health behaviour [21, 29, 36]. Ample number of studies have also found a positive correlation between external LOC and mental illness experiences [40-42]; which in turn suggest that the varying degrees and types of mental illness (including psychotic and non-psychotic) experiences tend to make the sufferer more prone to external LOC. It has also been found that a relationship exists between what individuals from BME community perceive to be the aetiology of their mental illness experiences and their LOC orientation [40]. In the light of this, the aim of this study was to assess the perceived control of the targeted groups via the lens of internal-external locus of control, as a possible explanation for the observed disparities in mental health outcomes and to identify potential solution from the results. 


\section{Study design and Sample}

Mental health service users who self-identified as of African and Caribbean origin were approached by researcher to participate in the study at the drop-in services of local charity organisations where they accessed and participated in recovery support projects and socialisation activities. Other inclusion criterion are male or female aged between 18 and 65, a diagnosis of a mental disorder, experience of discharge from psychiatric hospitals, not experiencing any form of psychosis but were mentally stable; able to understand the contents of the research information package and consent requirements; capable of providing informed consent, and to complete or be supported to complete the questionnaires. The suitability was determined with the support of the managers and members of staff of the community organisations who are familiar with and had been providing services to the participants. Ethical approval was granted by the University's ethics committee. A total of fifty respondents were found to have completed the two sets of questionnaires by the cut-off date, and formed the total sample used for this study, with no rejection. The demographic distribution of the participants is illustrated in Table 1 below. The mean age was 40 years (range of 25 to 56 years). From the fifty participants, seventeen were of African origin (34\%) and 33 participants were of Caribbean origin $(66 \%)$.

Table 1 -Demographic distribution

\begin{tabular}{|l|lc|}
\hline Variable & Results & \\
\hline Gender & Male & $25(50 \%)$ \\
& Female & $25(50 \%)$ \\
\hline Ethnic origin & Caribbean & $33(66 \%)$ \\
& African & $17(34 \%)$ \\
\hline Age & Mean: & 40 \\
& Range: & $25-56$ \\
\hline
\end{tabular}

The number of participants and resultant equal gender distribution was coincidental, as the total number of questionnaires collected were counted by the researcher only during inputting and analysis into Statistical Package for the Social Sciences (SPSS) [44], after the allocated cut-off date of the research schedule.

\section{Measures}

Participants were administered two sets of questionnaires: General Locus of Control (GLOC) [42], an abridged version of Rotter's original questionnaire [22], and Mental Health Locus of Control (MHLOC), [46]. The 13 pair statement GLOC questionnaire [45], invited the participants to choose by a tick, one statement, indicating internality or externality $(a$, or $b)$ they agree with from each pair of statement. This version was adopted for this study as it is shorter with a smaller number of paired statements (only thirteen pairs compared to the older versions which ranged between twenty-three to twenty-nine pairs) [22, 47]. It is also deemed as a more updated version, more user friendly, less cumbersome and time consuming for the participants as they were also requested to complete the Mental Health Locus of Control questionnaire [46]. The scoring guide for the GLOC is shown below (Table 2):

Table 2- GLOC -Scoring guide

SCORING OF 13 PAIRS OF STATEMENTS

$\begin{array}{lll}0-2 \text { scores } & - & \text { INTERNAL LOC } \\ 3-7 \text { scores } & - & \text { MODERATE EXTERNAL LOC } \\ 8-13 \text { scores } & - & \text { HIGH EXTERNAL LOC }\end{array}$

Explanation: This is a scoring guide for General Locus of Control Scale. It indicates that scores below two places the participant on internal LOC; a score between three and seven places the participant on a moderate external Locus of control, while scores between 8 and thirteen places the participant between high and extreme external LOC spectrum. 
Improving Mental Health Outcomes for Black and Minority Ethnic Communities: A Quantitative Study into Perception of Control

The Mental Health Locus of Control questionnaire [46] used for this study consists of a total of 22 statements in which participants indicate their level of agreement by ticking on the 6-points Likert scale, (Strongly disagree, etc.). The 22 item statements consist of 8 internals and 14 externals randomly dispersed amongst the numbers, and each participant gets a 1 for Strongly disagree, a 2 for Disagree, etc. for each statement. A scoring guide for the MHLOC is included in Table 3 below along with explanation.

Table 3- MHLOC-Scoring guide

\begin{tabular}{|l|l|}
\hline SCORING OF 22 MENTAL HEALTH LOCUS OF CONTROL STATEMENTS \\
22 scores - & MINIMUM SCORE, INTERNAL EXTREME MHLOC \\
23 to 77 scores - & INTERNAL MHLOC TO MID POINT EXTERNALITY \\
$77-132$ scores - & HIGH TO EXTREME EXTERNAL MHLOC
\end{tabular}

Explanation: This guide indicates that as the lowest score possible for each statement on the Likert scale is one and the highest score is six, the total scores available is between $1 \times 22$ and $6 \times 22=22$ and 132). With a range of between 22 and 132 scores, it indicates that 22 is the minimum available score which places the participant on extreme internal MHLOC. Scores higher than 22 and up to 77 indicates a range between internality and midpoint of external MHLOC. Scores between 77 and 132 indicates high to extreme externality. The basic principle is that the lower the MHLOC scores the higher the internality in MHLOC, and vice versa [46].

The two instruments were combined in preference for the only other available Mental Health LOC Scale [40], as this was designed based on the identified potential expectations of patients when they actively seek health services and was considered of a narrower scope [48]. It was also not considered applicable to the population group who participated in this study, as they had already passed through the mental health services admission system and were therefore situationally different in comparison to patients who visited hospitals and were actively seeking health services. The chosen MHLOC scale [46] is also preferred to the health LOC scale and the Multidimensional Health Locus of Control [49], as it is deemed to be more specific and has a higher strength of predictability of outcome for mental health contexts [48]. It is also intended that an increased understanding of the participants' LOC orientation could be achieved by combining a non-context-specific approach of measurement obtainable from the general locus of control (GLOC) instrument with a mental health specific measurement obtainable from the Mental Health Locus of Control (MHLOC) scale.

\section{Analysis}

A descriptive analysis of the two questionnaires were conducted using a computerised program, Statistical Package for the Social Sciences (SPSS) [41]. This includes frequency distribution, gender, ethnicity and age profiles and other comparative variables, in addition to reliability tests.

\section{Results}

\subsection{General Locus of Control (GLOC)}

\subsubsection{Frequency distribution of (GLOC) scores}

The frequency distribution shows the number of participants who scored between the lowest available score of 2 and the highest of 12 on the general locus of control scale indicates that only one participant earned 2 GLOC scores, one participant earned three GLOC scores, eight participants earned four GLOC scores respectively, indicating that only one out of the fifty participants had a strong internal locus of control. The results also indicate a mean of 6.46 and a standard deviation of 2.062. Most of the participants (48) scored between three and 12 points, which indicates between a moderate and high external locus of control. A total of 33 participants $(66 \%)$ had moderate external LOC with scores between 3 and 7; this includes five, six and seven participants who earned eight, seven and nine scores respectively. A total of 16 participants (32\%) scored higher than 8, placing them into a strong external LOC spectrum. This result 
Stephen Joseph and Frank Keating., Adv. J Social Sci.; Vol. 8, Issue 1, pp: 37-53, 2021

suggests that the externality in the general LOC of the participants ranged from moderate to high, with 66 percent in the moderate range and 32 percent in the high range.

\subsubsection{Gender distribution GLOC}

The GLOC frequency distribution by gender (Table 4), indicates an even spread of externality between the genders, with almost equal numbers of male and female participants being placed within the moderate externality and high externality. Although equal numbers of both genders participated in the study, the only participant who earned two scores and falling within extreme internal LOC was male, while the participant who earned the highest score of twelve (close to the highest level of externality) was also male. Seventeen female participants and sixteen males earned between three and seven scores (moderate externality), although no female participant earned three scores. Eight participants from each gender earned between eight and twelve scores (high externality), although two female participants earned ten scores while no male participant earned that number of scores.

Table 4- GLOC scores per gender

\begin{tabular}{|l|l|l|l|l|l|l|l|l|l|l|l|}
\hline $\begin{array}{l}\text { No. of } \\
\text { GLOC } \\
\text { Scores }\end{array}$ & 2 & 3 & 4 & 5 & 6 & 7 & 8 & 9 & 10 & 12 & Total \\
\hline Gender & & & & & & & & & & \\
\hline Male & 1 & 1 & 3 & 5 & 3 & 4 & 5 & 2 & 0 & 1 & 25 \\
\hline Female & 0 & 0 & 5 & 3 & 4 & 5 & 3 & 3 & 2 & 0 & 25 \\
\hline Total & $\mathbf{1}$ & $\mathbf{1}$ & $\mathbf{8}$ & $\mathbf{8}$ & $\mathbf{7}$ & $\mathbf{9}$ & $\mathbf{8}$ & $\mathbf{5}$ & $\mathbf{2}$ & $\mathbf{1}$ & $\mathbf{5 0}$ \\
\hline
\end{tabular}

\subsubsection{Comparison of mean GLOC scores per gender}

A further analysis was carried out to assess any difference in the mean and standard deviation of the GLOC scores between the genders. The results indicate that the men had a relatively lower mean GLOC score (6.3) compared to female (6.6). However, the standard deviation was slightly higher for the male compared to the female of (1.9); suggesting that the males may have a comparatively lower externality (more internal) in general locus of control. As the results indicate that a conclusion could not be arrived at as a result of observed insignificant difference in the comparative standard deviation, further tests were carried out to assess significance in relation to gender by testing any significant difference between the two-gender means. An independent sample test resulted in a negative .476 (-.476). This is highly significant test result which shows that the mean LOC between male and female are significantly different, (based on using an alpha of .05); which in turn suggests that there are significant differences in the LOC between the two genders. It also indicates that further investigation is desirable. The low number of samples also means that the results need to be treated with caution as a higher sample could also throw more light to the level of significance.

\subsubsection{Participation by age range}

The results of an analysis of the GLOC frequency distribution in relation to the ranges of age on one hand and the distribution profile of the GLOC scores within the age ranges (Tables 5 and 6) indicate that the participants within the 25-34 age group recorded the least level of externality with the lowest GLOC scores of $6,(12 \%$ of the total); this suggests that higher externality may correlate with increase in age. However, the GLOC scores of this age group were spread out evenly between 5 and 10 GLOC scores as they scored one each, placing them between moderate to mid- high externality. The 35-44 age group were also placed within the moderate to high externality, although in comparatively higher number as they scored a total of ten of their total scores of 14 between 3 and 7 score band (moderate external) and four for high externality. Participants of 45-54 age range scored highest total of 23, made up of 1 internal, 16 moderate to high external scores, and 6 high external. The 55-64 age group recorded the least scores of 7, from which four were within moderate to high external scale and three within high externality. 
Table 5- GLOC participation per age range

\begin{tabular}{|l|l|l|l|}
\hline $\begin{array}{l}\text { Age } \\
\text { range }\end{array}$ & Frequency & Percentage & $\begin{array}{l}\text { Cumulative } \\
\text { percent }\end{array}$ \\
\hline $25-34$ & 5 & 12 & 12 \\
\hline $35-44$ & 14 & 28 & 40 \\
\hline $45-54$ & 23 & 46 & 86 \\
\hline $55-64$ & 7 & 14 & 100 \\
\hline Total & $\mathbf{5 0}$ & $\mathbf{1 0 0}$ & \\
\hline
\end{tabular}

Table 6- GLOC scores distribution per age range

\begin{tabular}{|l|l|l|l|l|l|l|l|l|l|l|l|}
\hline $\begin{array}{l}\text { No. of } \\
\text { GLOC } \\
\text { Scores }\end{array}$ & 2 & 3 & 4 & 5 & 6 & 7 & 8 & 9 & 10 & 12 & Total \\
\hline Age range & & & & & & & & & & \\
\hline $25-34$ & 0 & 0 & 0 & 1 & 1 & 1 & 1 & 1 & 1 & 0 & 6 \\
\hline $35-44$ & 0 & 0 & 2 & 3 & 0 & 5 & 2 & 1 & 1 & 0 & 14 \\
\hline $45-54$ & 1 & 0 & 5 & 3 & 5 & 3 & 3 & 2 & 0 & 1 & 23 \\
\hline $55-64$ & 0 & 1 & 1 & 1 & 1 & 0 & 2 & 1 & 0 & 0 & 7 \\
\hline Total & $\mathbf{1}$ & $\mathbf{1}$ & $\mathbf{8}$ & $\mathbf{8}$ & $\mathbf{7}$ & $\mathbf{9}$ & $\mathbf{8}$ & $\mathbf{5}$ & $\mathbf{2}$ & $\mathbf{1}$ & $\mathbf{5 0}$ \\
\hline
\end{tabular}

\subsubsection{Correlation Test -gender}

A Pearson correlation coefficient test was conducted between the total sum of GLOC scores by participants and their gender. The Pearson correlation measures the degree of the linear relationship between two variables. Positive or negative relationships can be found between two variables which indicates that a change in one could lead to a change in another variable [44]. Table 7 below shows the results of the Pearson correlation test, indicating that the Pearson correlation is negative .31 and the p-value is .03. The alpha of .05 and two-tailed test rule allows for a positive or a negative correlation. A decision rule for all tests indicates that if $\mathrm{p}$ is less than or equal to .05 , the test is significant, and if $\mathrm{p}$ is greater than .05 , the difference is not significant [44]. This indicates a significant relationship between the GLOC scores and gender. As the $\mathrm{p}$-value in this output is .03; (less than .05), which also indicates that the difference is significant. Degree of freedom $\mathrm{r}=(50-2=48$, which is the sample size of 50 minus 2); Correlation coefficient is $=-.31$; $\mathrm{P}$ value $=.03$. There is therefore a significant negative relationship between the GLOC scores and the gender of the participants in this study, indicating that there could be differences in profile of GLOC on account of gender. The negative relationship indicated suggests that a higher GLOC externality in men would indicate a higher internality in women and vice versa. The comparative mean results indicate that men have a lower externality scores, suggesting that women are likely to be more external in their GLOC. This result suggests a confirmation of the test of significance (test), which indicates that gender differences could impact on GLOC orientation.

Table 7 - Correlation test GLOC- gender

\begin{tabular}{|l|l|l|l|}
\hline & & Total Sum & Gender \\
\hline Total Sum & Pearson Correlation & 1 & $-.313^{*}$ \\
\hline & Sig. (2-tailed & & .027 \\
\hline & N & 50 & \\
\hline Gender & Pearson Correlation & $-.313^{*}$ & 1 \\
\hline & Sig. (2-tailed) & .027 & \\
\hline & N & 50 & 50 \\
\hline
\end{tabular}




\subsubsection{Group comparison- per ethnic distribution of GLOC}

A further analysis was conducted to identify any differences in the GLOC results between the two groups of ethnicities- The African and the Caribbean populations. The ethnic distribution of participants in Table 8 below, shows that out of the total number of fifty participants a total of 33 (66 per cent) were of Caribbean heritage; this is almost double the number of participants of African heritage, totalling seventeen (34\%). The difference in participation rates is likely to have impact on the results due to a comparatively higher representation of one group to the other.

Table 8- Ethnic distribution of participants

\begin{tabular}{|l|l|l|}
\hline Ethnic origin & Frequency & Percent \\
\hline Caribbean & 33 & $66 \%$ \\
\hline African & 17 & $34 \%$ \\
\hline Total & $\mathbf{5 0}$ & $\mathbf{1 0 0}$ \\
\hline
\end{tabular}

\subsubsection{GLOC Scores per ethnic origin}

The rate of participation and GLOC scores per ethnic origin (in table 9) below, suggests that the Caribbean population in this sample may have an overall higher level of externality compared to their African counterparts. The only male participant (as indicated in the gender table analysed earlier) who earned two scores (internal) was of African origin, while the only male participant who earned the highest externality score of twelve was of the Caribbean group. A total of 22 Caribbean participants earned between three and seven (moderate external) scores; this represents 67 per cent of the 33 Caribbean sample. This is double in number in comparison to 11 participants of African origin within this range of externality, as the Caribbean participants were numerically double in total number (33 compared to 17 above). However, $65 \%$ of the African sample (17) fell within this range of externality scores, indicating an almost equal state of externality in terms of number between the two groups. Furthermore, although seven Caribbean participants earned eight scores compared to one earned by an African participant, a total of eleven Caribbean participants earned between 8 and 12 (high external) scores compared to five African participants, again representing double comparative frequency. This seems to be moderated by the difference in participation numbers as the Caribbean participants represented almost double the number of African participants.

Table 9- GLOC scores per ethnic origin

\begin{tabular}{|l|l|l|l|l|l|l|l|l|l|l|l|}
\hline $\begin{array}{l}\text { No. of } \\
\text { GLOC } \\
\text { Scores }\end{array}$ & 2 & 3 & 4 & 5 & 6 & 7 & 8 & 9 & 10 & 12 & Total \\
\hline Ethnic origin & & & & & & & & & & \\
\hline Caribbean & 0 & 1 & 7 & 5 & 4 & 5 & 7 & 1 & 2 & 1 & 33 \\
\hline African & 1 & 0 & 1 & 3 & 3 & 4 & 1 & 4 & 0 & 0 & 17 \\
\hline Total & $\mathbf{1}$ & $\mathbf{1}$ & $\mathbf{8}$ & $\mathbf{8}$ & $\mathbf{7}$ & $\mathbf{9}$ & $\mathbf{8}$ & $\mathbf{5}$ & $\mathbf{2}$ & $\mathbf{1}$ & $\mathbf{5 0}$ \\
\hline
\end{tabular}

\subsection{Mental Health Locus of Control (MHLOC)}

\subsubsection{Frequency distribution}

The Histogram (Table 10) below shows the frequency distribution of the Mental Health Locus of Control scores by all the 50 participants. It records a mean of 83.28 and standard deviation of 19.9. The results suggest that more than $50 \%$ of the participants fall within high external mental health LOC, although there is no indication of extreme externality in the results.

Although the minimum possible score was 22, the range of scores this result was between 33 and 120 . The lowest number of scores of 33 was earned by one participant, while the highest number of scores of 120 was also earned by one participant. Out of the fifty participants, 20 participants $(44 \%)$ earned between the 
Improving Mental Health Outcomes for Black and Minority Ethnic Communities: A Quantitative Study into Perception of Control

lowest score of 33 and the midpoint score of 77 , indicating that almost half of the participants have between low and mid-moderate external mental health LOC. Twenty eight participants $(56 \%)$ earned more than 77 scores (between 79 and 120 scores), indicating high external MHLOC. None of the participants earned scores higher than 120, indicating that their level of LOC externality may not be at the extreme end.

\section{Table 10- Histogram of MHLOC score profile}

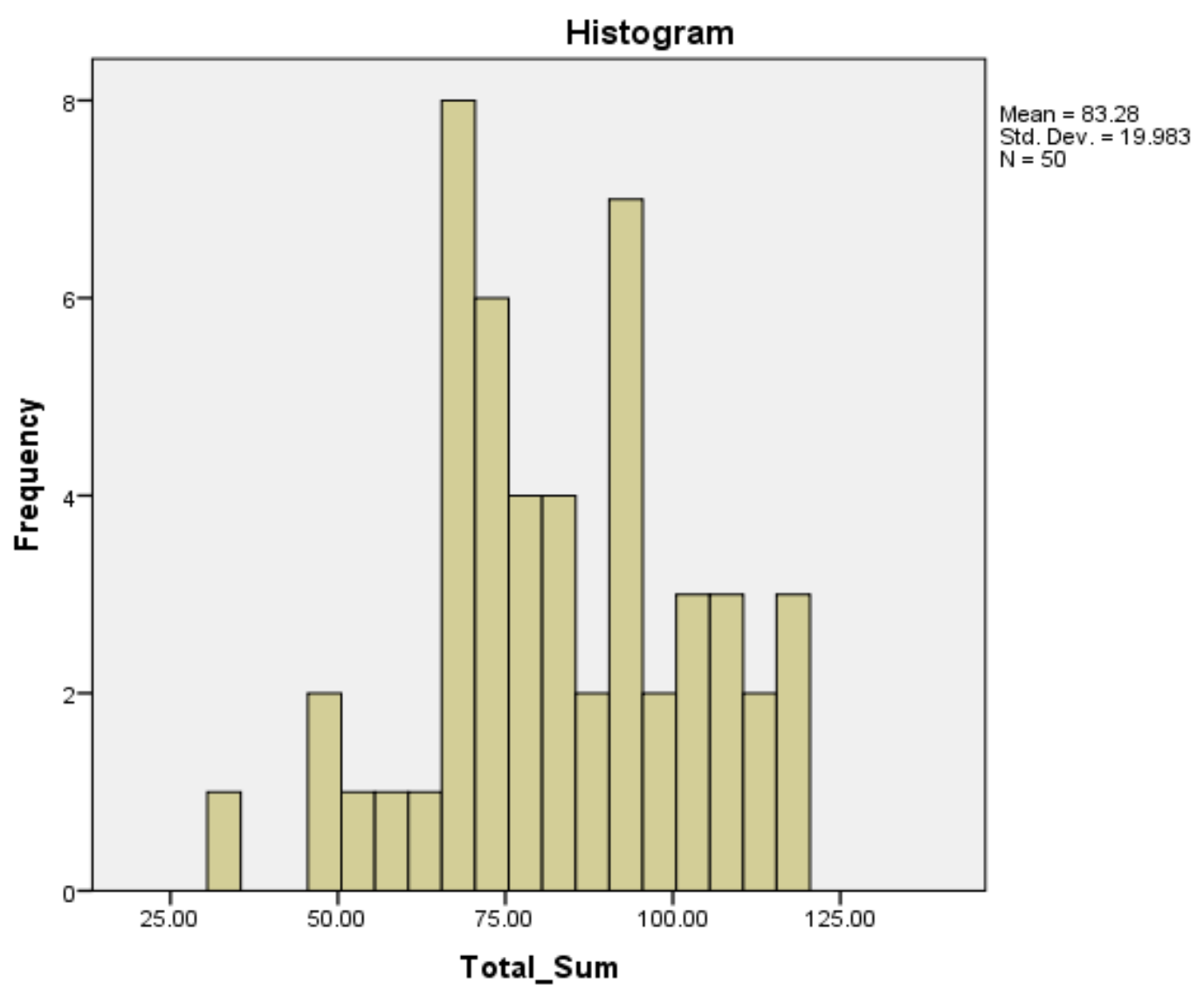

\subsubsection{Comparison- Gender MHLOC scores}

The results of the MHLOC scores by gender suggests that women were more located within high externality than men. A total of 8 men scored between 33 and 77, (the midpoint of externality), compared to 22 women, which represents more than triple this number. This shows that more women $(44 \%)$ fell within the low and mid-moderate external mental health LOC scale. In addition, a total of 17 men earned scores between 79 and 120 compared to 28 women; this also indicates that more women (over 56\%) fell within the high external mental health spectrum in comparison to the men.

\subsubsection{Comparison- Gender mean MHLOC scores}

The results of the mean MHLOC scores by gender shown in (Table 11), suggest that although there is a higher mean recorded for men, there is marked differences in the mean and standard deviation of the two groups. It also indicates that further investigation is warranted, as externality has been observed for female in terms of face value difference. A comparison of the results indicates a higher mean of 89.5 for men compared to 77.08 for women. Although the mean MHLOC for women is lower, suggesting a higher internality than the men, the standard deviation is however higher (20.83 for female compared to 17.35 for male). 
Stephen Joseph and Frank Keating., Adv. J Social Sci.; Vol. 8, Issue 1, pp: 37-53, 2021

Table 11-Comparison of mean MHLOC per gender

\begin{tabular}{|l|l|l|l|l|}
\hline Gender & Number & Mean & Std Deviation & Std Error Mean \\
\hline Male & 25 & 89.5 & 17.35 & 3.5 \\
\hline Female & 25 & 77.0 & 20.8 & 4.2 \\
\hline Total & $\mathbf{5 0}$ & & & \\
\hline
\end{tabular}

\subsubsection{T-TEST -Mean MHLOC -Gender}

Further comparison of the gender mean MHLOC through independent samples test was conducted with results in (Table 12) below. It showed a $\mathrm{p}$ value of .027, (lower than the 0.05), indicating a significant relationship between gender and MHLOC. However, as the test result is at 2.27, it also suggests that further investigation is warranted in this regard by future research, as the frequency distribution suggests externality for female participants.

Table 12- Independent Samples Test-MHLOC-Gender

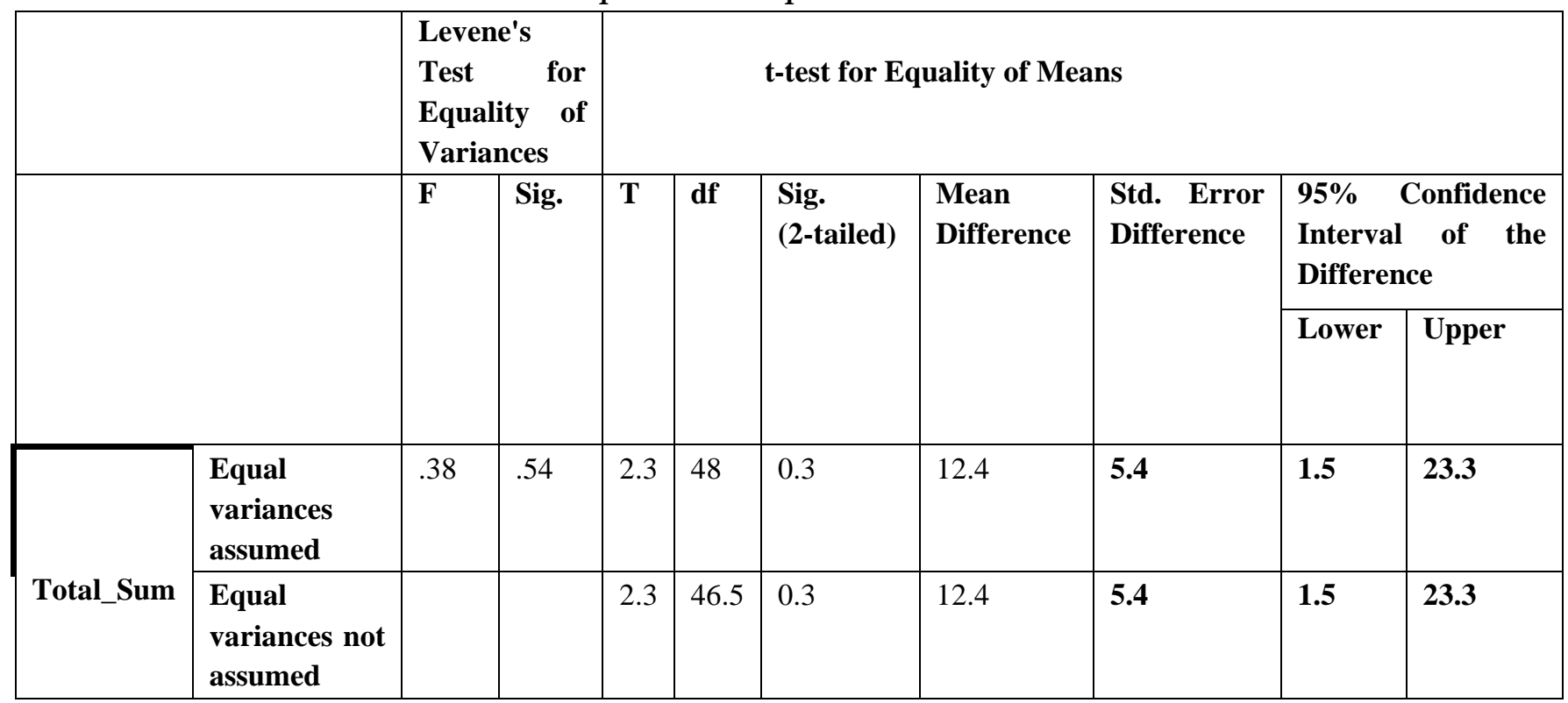

\subsubsection{Ethnicity MHLOC scores}

The MHLOC scores per ethnicity, suggests that the Caribbean participants had higher level of externality than their African counterparts, as 14 Caribbean participants scored between 33 and 77 compared to 8 African participants. This means that almost double the number of Caribbean participants is placed within the low and mid-moderate external mental health LOC scale. In addition, 19 Caribbean participants compared to 9 Africans earned between 79 and 120 scores, which represents more than $57 \%$ of the Caribbean sample compared to $52 \%$ for the African sample. It also indicates that more than double the number of Caribbean participants fell within the high externality of MLOC spectrum in comparison of the African participants.

\subsubsection{Comparison of mean MHLOC per ethnic origin}

The results of this mean and standard deviation of the MHLOC scores per ethnic origin shown in Table 13 below, suggests that the comparative externality status of the Caribbean group from the frequency distribution merits further investigation. The Caribbean participants' mean MHLOC (81.8 and standard deviation (19.5) is lower than the African participants (86.1); and (21.1) respectively. This shows that although the frequency distribution may indicate that the Caribbean participants scored higher in externality, the mean score and standard deviation takes into consideration the rate of participation between 
Improving Mental Health Outcomes for Black and Minority Ethnic Communities: A Quantitative Study into Perception of Control

the two groups, the dispersion rate and the scores [44]. The mean results indicate that although the Caribbean participants have higher level of externality in absolute terms, the mean MHLOC is lower, and the rate of dispersion in the standard deviation for the Caribbean group is also comparatively closer to the mean, thereby suggesting that the rate of externality merits further investigation.

Table 13- Mean MHLOC per ethnic origin

\begin{tabular}{|l|l|l|l|}
\hline Ethnicity & Mean MHLOC & Number & Std. Deviation \\
\hline Caribbean & 81.8 & 33 & 19.6 \\
\hline African & 86.1 & 17 & 21.1 \\
\hline
\end{tabular}

\subsubsection{T-TEST-Ethnicity mean MHLOC}

As this difference could not however be considered significant without conducting more tests in this regard, an independent samples t-test, was also carried out as with the comparisons conducted with the GLOC results. A t-test is conducted to decipher the significance in differences between the two means. The results of the test for the ethnicity MHLOC means of this sample (Table 14) below shows a test result of negative 0.717 (-.72), which is less than .05, the test of significance level (based on using an alpha of .05). This suggests that there is also a significance in the differences in the two means of ethnicity. However, as the two tailed significance is higher at .477 , this result is to be taken with caution, in addition to the low sample size and the comparative levels of participation, between the two groups, as the Caribbean participants almost doubled the African participants in number. It also seems to corroborate the findings on the test on GLOC, indicating a need for further investigation.

Table 14 -T Test of Ethnic MHLOC mean

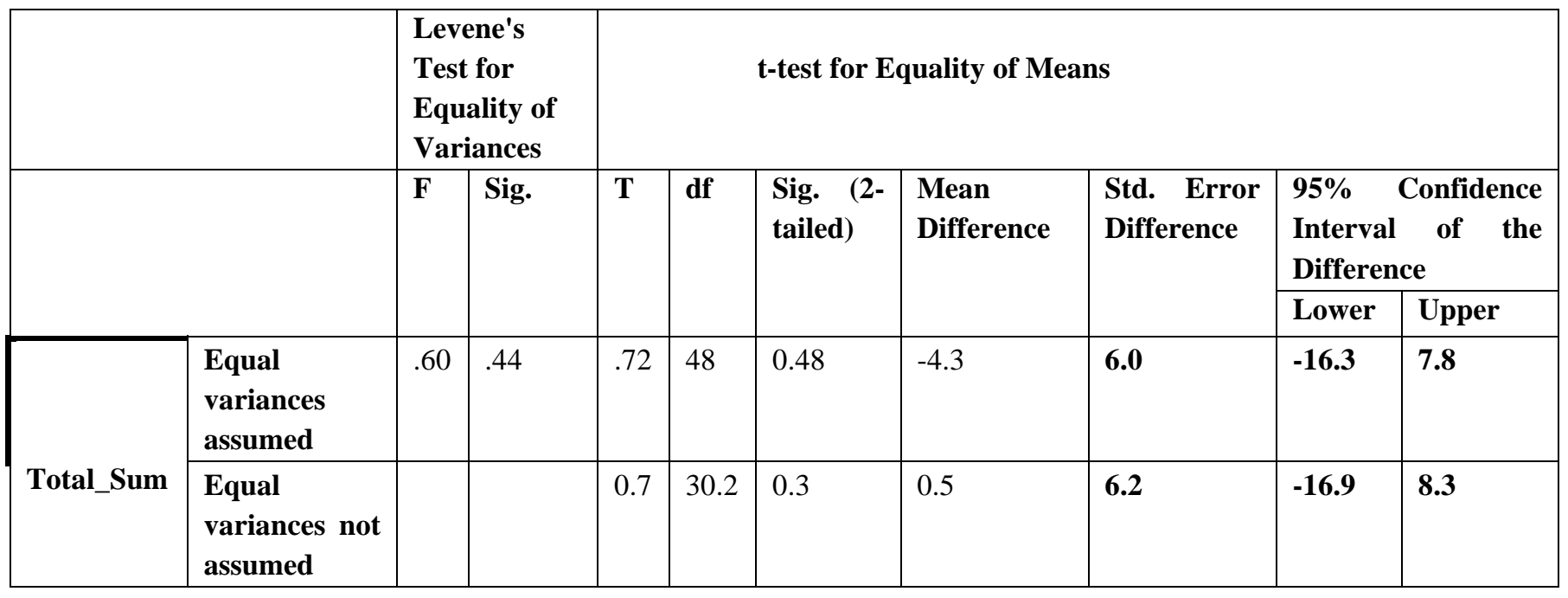

\subsubsection{Age range comparison of participation}

Table 15 below shows the participation profile for each age range, indicating that six people below 25 participated in this study, representing the lowest 12 per cent of the fifty participants. The participants aged between 45 and 54 made up $46 \%$ of the sample, while 14\% were between 35 and 44 years. Seven persons aged between 55 and 64 made up seven per cent of the fifty participants. As there were no participants over 65 , it indicates that this study did not represent the views of older age group of 65 and older.

Table 15- Age range MHLOC participation table

\begin{tabular}{|l|l|l|l|}
\hline Age range & Frequency & Percent & Cumulative Percent \\
\hline $25-34$ & 6 & 12 & 12 \\
\hline $35-44$ & 14 & 28 & 40 \\
\hline $45-54$ & 23 & 46 & 86 \\
\hline $55-64$ & 7 & 14 & 100 \\
\hline Total & 50 & 100 & \\
\hline
\end{tabular}


Stephen Joseph and Frank Keating., Adv. J Social Sci.; Vol. 8, Issue 1, pp: 37-53, 2021

\subsubsection{Age range MHLOC score}

A comparison of the scores by the participants in relation to their age groups are shown in Table 16 below titled Age range MHLOC scores.

Table 16- Age range MHLOC scores

\begin{tabular}{|c|c|c|c|c|c|}
\hline \multirow{2}{*}{$\begin{array}{l}\text { MHLOC } \\
\text { Scores }\end{array}$} & \multicolumn{4}{|c|}{ Age range } & \multirow[t]{2}{*}{ Total } \\
\hline & $25-34$ & $35-44$ & $45-54$ & 55-64 & \\
\hline 33 & 0 & 1 & 0 & 0 & 1 \\
\hline 46 & 0 & 1 & 0 & 0 & 1 \\
\hline 50 & 0 & 0 & 0 & 1 & 1 \\
\hline 53 & 0 & 1 & 0 & 0 & 1 \\
\hline 58 & 0 & 0 & 1 & 0 & 1 \\
\hline 64 & 0 & 0 & 1 & 0 & 1 \\
\hline 66 & 0 & 1 & 1 & 1 & 3 \\
\hline 67 & 1 & 0 & 0 & 0 & 1 \\
\hline 68 & 1 & 0 & 0 & 0 & 1 \\
\hline 69 & 0 & 0 & 1 & 1 & 2 \\
\hline 70 & 0 & 0 & 1 & 0 & 1 \\
\hline 71 & 0 & 1 & 1 & 0 & 2 \\
\hline 72 & 0 & 0 & 1 & 0 & 1 \\
\hline 73 & 0 & 1 & 0 & 0 & 1 \\
\hline 74 & 0 & 0 & 0 & 1 & 1 \\
\hline 75 & 0 & 1 & 0 & 0 & 1 \\
\hline 76 & 1 & 0 & 0 & 0 & 1 \\
\hline 77 & 0 & 0 & 1 & 0 & 1 \\
\hline 79 & 1 & 0 & 1 & 0 & 2 \\
\hline 81 & 0 & 1 & 0 & 0 & 1 \\
\hline 83 & 0 & 1 & 0 & 0 & 1 \\
\hline 84 & 0 & 0 & 1 & 0 & 1 \\
\hline 85 & 0 & 1 & 0 & 0 & 1 \\
\hline 86 & 0 & 1 & 0 & 0 & 1 \\
\hline 89 & 0 & 0 & 0 & 1 & 1 \\
\hline 91 & 0 & 0 & 1 & 0 & 1 \\
\hline 92 & 0 & 0 & 1 & 0 & 1 \\
\hline 93 & 1 & 0 & 1 & 1 & 3 \\
\hline 94 & 0 & 0 & 1 & 0 & 1 \\
\hline 95 & 0 & 1 & 0 & 0 & 1 \\
\hline 96 & 0 & 0 & 1 & 0 & 1 \\
\hline 100 & 0 & 1 & 0 & 0 & 1 \\
\hline 101 & 0 & 0 & 1 & 0 & 1 \\
\hline 102 & 0 & 0 & 1 & 0 & 1 \\
\hline 104 & 0 & 0 & 1 & 0 & 1 \\
\hline 108 & 0 & 0 & 1 & 0 & 1 \\
\hline 110 & 0 & 0 & 2 & 0 & 2 \\
\hline 112 & 0 & 1 & 0 & 0 & 1 \\
\hline 115 & 0 & 0 & 0 & 1 & 1 \\
\hline 117 & 0 & 0 & 1 & 0 & 1 \\
\hline 118 & 0 & 0 & 1 & 0 & 1 \\
\hline 120 & 1 & 0 & 0 & 0 & 1 \\
\hline Total & 6 & 14 & 23 & 7 & 50 \\
\hline
\end{tabular}


Improving Mental Health Outcomes for Black and Minority Ethnic Communities: A Quantitative Study into Perception of Control

The results show that the 45-54 age groups lean to higher externality than other age groups. The table shows that only three participants between the ages of 25 and 34 scored between 33 and 77 compared to 7 for 35-44 age range, 8 for 45-54, and four for the 55 -64 age range. This means that more people within the 55-54 and 35-44 age ranges fall within the low and mid-moderate external mental health LOC scale. Again, only three people within 25 and 34 age range scored between 79 and 120 in comparison to seven for 3544, fifteen for the 45-54, and three also for the 55 - 64 group. This suggests that more people within the 4554 age group are placed within the high external mental health LOC spectrum in comparison to the other age groups. In addition, it further suggests that this age group recorded highest number of participants (23, or $46 \%$ ) with MHLOC scores of between moderate and high externality than the rest of the age groups.

\subsubsection{Comparison -mean MHLOC per Age range}

A comparison of the mean MHLOC scores profiles per age range in the Table 17 below, shows that the 35-44 group has the lowest mean MHLOC scores with 75.64 (higher internality), followed by the 45-54 age group with 79.43. However, the 45-54 age group recorded the lowest comparative standard deviation of 18.2, indicating that this group had the standard deviation which is the closest in dispersion in relation to the mean. This suggests that the results warrant more in-depth study, as it is inconclusive in view of the frequency numbers of this group (23) that fall within externality spectrum in comparison to other age groups, as well as the low sample size. As only pair-wise t-test option is available, which could only conduct specific age group comparisons, it suggests that further investigations in relation to age group profiles of MHLOC may be desirable.

Table 17- Comparison of mean MHLOC per age range

\begin{tabular}{|l|l|l|l|}
\hline Age range & Mean & Number & Std. Deviation \\
\hline $25-34$ & 83.8 & 6 & 20.05 \\
\hline $35-44$ & 75.6 & 14 & 21.3 \\
\hline $45-54$ & 88.9 & 23 & 18.2 \\
\hline $55-64$ & 79.4 & 7 & 21.3 \\
\hline
\end{tabular}

\subsection{Summary of results}

As shown in the table of summary of the results in Summary Table 18 below, several parts of the results have indicated that a profile of between moderate and high external LOC has been exhibited by the participants on both scales, with some variations in profiles for each of the results. The GLOC scores specifies the existence of varying scale of differences in the Internal-External profile of the participants, although the level of externality was more pronounced in comparison with the MHLOC results. There is an even spread of externality between genders, although there is an indication of lower externality in men than women. Younger people were also indicated to be more internal than older aged groups, while the African participants were also indicated to be less external in GLOC than their Caribbean counterparts.

The MHLOC scores also shows that participants recorded between moderate and high externality in general. However, there are varying degrees of differences in the MHLOC profiles in terms of age, ethnicity and gender. More females were indicated to be of higher externality than the males while people within younger age groups of between 35 and 44 years are indicated to have higher internality. The results of the correlation coefficient for both results shows that gender is a significant issue in both GLOC and MHLOC scores, which merits attention. Although, the Caribbean group were also indicated to be within comparatively higher MHLOC externality the results are not conclusive due to the profile of the mean and standard deviation results and further statistical significance tests. The relatively small sample size also suggests that further investigation is desirable in order to explore the differences in MHLOC profiles of the A \& C groups. The GLOC questionnaire was inconclusive in relation to test of reliability, as there was no parameter to assess its reliability due to the absence of Likert scale format for the questionnaire. The result of a test of reliability of the MHLOC scale resulted in a high Cronbach's alpha score from the tool itself as well as in relation to the deletion of each of the question item, thereby indicating that the tool used 
Stephen Joseph and Frank Keating., Adv. J Social Sci.; Vol. 8, Issue 1, pp: 37-53, 2021

is reliable. The MHLOC reliability test has also been found to be similar to the reliability results found by the authors who designed the instrument [46], as they had found an 'alpha coefficient of MHLC (of) .84' [46:155].

Table 18- Summary of GLOC and MHLOC results

\begin{tabular}{|c|c|c|c|c|c|c|c|c|c|c|c|}
\hline \multicolumn{6}{|c|}{ GENERAL LOCUS OF CONTROL (GLOC) } & \multicolumn{6}{|c|}{$\begin{array}{lllll}\text { MENTAL } & \text { HEALTH } & \text { LOCUS } & \text { OF } & \text { CONTROL } \\
\text { (MHLOC) } & & & & \end{array}$} \\
\hline $\begin{array}{l}\text { Demographic } \\
\text { distribution }\end{array}$ & Total & $\begin{array}{l}\text { Min } \\
\text { score }\end{array}$ & $\begin{array}{l}\text { Max } \\
\text { score }\end{array}$ & Mean & $\begin{array}{l}\text { St } \\
\text { Dev }\end{array}$ & $\begin{array}{l}\text { Demograp } \\
\text { hic } \\
\text { distribution }\end{array}$ & Total & $\begin{array}{l}\text { Min } \\
\text { score }\end{array}$ & $\begin{array}{l}\text { Max } \\
\text { score }\end{array}$ & $\begin{array}{l}\text { Mea } \\
\mathrm{n}\end{array}$ & St Dev \\
\hline Number & $\begin{array}{l}50 \\
(100 \%)\end{array}$ & 2 & 12 & 6.4 & 2.0 & Number & $\begin{array}{l}50 \\
(100 \%)\end{array}$ & 33 & 120 & 83.3 & 19.9 \\
\hline \multicolumn{12}{|l|}{ Gender } \\
\hline Male & $25(50 \%)$ & & & 6.3 & 2.2 & Male & $\begin{array}{l}25 \\
(50 \%)\end{array}$ & & & 89.4 & 17.4 \\
\hline Female & $\begin{array}{l}25 \\
(50 \%)\end{array}$ & & & 6.6 & 1.9 & Female & $\begin{array}{l}25 \\
(50 \%)\end{array}$ & & & 77.1 & 20.8 \\
\hline \multicolumn{2}{|l|}{ Age } & & & & & \multicolumn{2}{|l|}{ Age } & & & & \\
\hline Mean & 40 & & & & & Mean & 40 & & & & \\
\hline Range & $25-56$ & & & & & Range & $25-56$ & & & & \\
\hline \multicolumn{2}{|l|}{ Age range $\mathrm{LOC}$} & & & & & \multicolumn{2}{|c|}{ Age range LOC } & & & & \\
\hline $25-34$ & $6(12 \%)$ & & & 7.5 & 1.9 & $25-34$ & $6(12 \%)$ & & & 83.8 & 20.0 \\
\hline $35-44$ & $14(28 \%)$ & & & 6.6 & 1.8 & $35-44$ & $\begin{array}{l}14 \\
(28 \%)\end{array}$ & & & 75.6 & 21.3 \\
\hline $45-54$ & $23(46 \%)$ & & & 6.1 & 2.2 & $45-54$ & $\begin{array}{l}23 \\
(46 \%)\end{array}$ & & & 88.9 & 18.1 \\
\hline $55-64$ & $7(14 \%)$ & & & 6.1 & 2.3 & $55-64$ & $7(14 \%)$ & & & 79.4 & 21.3 \\
\hline \multicolumn{6}{|l|}{ TESTS } & \multicolumn{6}{|c|}{ TESTS } \\
\hline \multicolumn{2}{|c|}{$\begin{array}{l}\text { Pearson } \\
\text { coefficient: }\end{array}$} & -.31 & & & & \multicolumn{2}{|c|}{$\begin{array}{l}\text { Pearson correlation } \\
\text { coefficient: }\end{array}$} & -.31 & & & \\
\hline \multicolumn{2}{|c|}{$\begin{array}{l}\text { P value } \\
* \quad \text { Correlation is } \\
\text { significant at the } 0.05 \\
\text { level (2-tailed) for } \\
\text { Gender. }\end{array}$} & .03 & & & & \multicolumn{2}{|c|}{$\begin{array}{l}\text { P value } \\
* \quad \text { Correlation is } \\
\text { significant at the } 0.05 \\
\text { level (2-tailed) for } \\
\text { Gender. }\end{array}$} & .03 & & & \\
\hline \multicolumn{2}{|c|}{$\begin{array}{l}\text { Pearson } \\
\text { coefficient: }\end{array}$} & & & & & \multicolumn{2}{|c|}{$\begin{array}{l}\text { Pearson correlation } \\
\text { coefficient: }\end{array}$} & & & & \\
\hline Age & -.195 & & & & & Age & .085 & & & & \\
\hline \multirow{2}{*}{ Ethnicity } & .024 & & & & & Ethnicity & .103 & & & & \\
\hline & & & & & & \multicolumn{5}{|c|}{ Reliability of instrument - Cronbach's Alpha } & -0.87 \\
\hline
\end{tabular}

\subsection{Reliability test-MHLOC}

A test of reliability was conducted in order to assess the level of reliability of the MHLOC questionnaire.

The Cronbach alpha is used to measure the internal consistency of questionnaire [44]. The value of 0.7 or higher is considered to test the reliability of quantitative tools. Below are the results of the reliability test conducted - the Cronbach Alpha result. 
Improving Mental Health Outcomes for Black and Minority Ethnic Communities: A Quantitative Study into Perception of Control

Table 19 below contains the Cronbach's alpha test of reliability for the MHLOC questionnaire, which the indicates a scoring of .872 . This is higher than 0.7 , which is considered the baseline score for reliability [44].

Table 19 - Reliability test- Cronbach Alpha result

Reliability Statistics

\begin{tabular}{|l|l|}
\hline Cronbach's Alpha & Number of Items \\
\hline .872 & 22 \\
\hline
\end{tabular}

A further test into the Cronbach's alpha scores that would result if each of the twenty-two item questions were item deleted, also resulted in higher than 0.7 for each statement. This is a further test of the reliability of the MHLOC questionnaire, as it proves reliability of the instrument with an indication that the deletion of each question or statement would have no negative impact on the tool as it resulted in higher than 0.7.

\section{Discussion}

The results from this study suggest that despite the difference in the options provided in the two instruments, similar results were yielded, indicating some level of reliability. The scores indicated a high level of moderate and high externality in LOC for both A \& C participants in both general and mental health contexts. It means that although the GLOC did not provide the Likert scale type of responses, a higher percentage of the participants still chose to agree more with statements that favour external LOC. The MHLOC result also indicates that a high proportion of the participants (56 per cent) were spread between mid and high externality. The GLOC results suggest that there is a high likelihood that the sampled population perceives themselves to have a low sense of control over their lives. Apart from the two extreme cases of externality (12) and internality (2) recorded by the male participants, this gender distribution indicates a fair spread of internality and externality in GLOC between the male and female participants, which suggests that more in-depth study may be useful to decipher any differences in the LOC between genders. This result is also almost replicated in the MHLOC domain for this sample, as there is an indication of between a moderate and high external mental health LOC in the sample, although women were indicated to be more external. This suggests also that a high percentage of the sample perceived that their mental health is beyond their control, just as their general LOC leans more towards externality than internal. It also seems to indicate that individuals from A \& $\mathrm{C}$ heritage who have experienced mental health challenges are likely to have the view that their mental health are not likely to be impacted by their own input or the contribution they make in the health care processes. This is in view the findings from the literature that individuals with external LOC are inclined to consider that results are determined by outside forces such as luck, fate, or powerful others [21], and are likely to consider that exerting effort towards achieving an outcome a worthless exercise. It has also been asserted from a more recent study related to the impact of COVID-19 pandemic on mental health and Locus of Control, that in times of uncertainty 'feeling in control of one's fate therefore appears to be protective against negative mental health impact' [51:11].

The MHLOC results also applies to this, as literature also indicates that someone who leans on the external spectrum of LOC is perceived to not likely to engage with the health care process in an active manner, as they are likely to perceive that their effort is not likely to be rewarded. This is also relevant as a passive behaviour has been identified as characteristic of external LOC orientation in health care settings, resulting from perceived inability to control issues around their health [34, 51]. In contrast, literature also indicates that individuals who are of the internal LOC spectrum are likely to be more active and take ownership of their health care process as well as their relationship with the health care practitioners $[25,36]$.

The result from both instruments also appears to corroborate findings from the literature that people of the BME community have more external LOC than other populations [21, 4]. Having provided an opportunity to apply the instruments to a sample of A \& C community, this study has shown that this sub set of the BME community have a moderate to high external LOC. However, the previous studies have been generally based on individuals of BME backgrounds in different countries including Asian, Chinese and other cultures rather than focusing on specific A \& C people as has been conducted in this study. The 
Stephen Joseph and Frank Keating., Adv. J Social Sci.; Vol. 8, Issue 1, pp: 37-53, 2021

findings also highlight the desirability in assessing or decipher the factors that are likely to be causative or contributory to a high externality in LOC in individuals from A \& C backgrounds, and if there exist some specific causes of externality that the literature has identified, which are still applicable to the sampled population. As it has been indicated that promoting internal LOC in individuals can encourage them to take active participation in the decision making on their health [36,51], it also suggests a need to explore the possibility that the internal-external orientations could be subject to change with intervention or by raising awareness on issues that could be identified as causative factors for the external LOC orientations and address them [4]. A discovery of such factors would suggest that if individuals who lean towards an external LOC and other people who are supporting them in the particular setting could be made aware of the meaning of the externality status; there is a likelihood that they could be motivated as well as be supported to reconsider or pay attention to their outlook to life and, by implication, their approach and response to their general LOC and/or mental health care, as well as their health seeking behaviour. Recent assertion that individuals with internal locus of control tend to rely less on medical care than individuals on the externality spectrum [50], also lends credence to the necessity for internality in LOC to be promoted in mental health.

Although the tests conducted have indicated that gender is an issue of significance in both MHLOC and GLOC scores, the profile of participation in the quantitative part of this study suggests that further study could be useful to decipher and make more reliable deductions into differences in orientation between the two groups. This is due to the low number of participants, as it has been posited that quantitative data are usually more reliable when the participation numbers are as high as two hundred samples, as this will lend it to more in-depth analysis [44]. In addition, given that there was an uneven distribution in terms of the ethnic participation number, as the Caribbean group was more represented in this sample by almost twice the number of participants from the African group; an even number or close to even number of participants could provide a greater opportunity for more realistic comparison of specific areas including gender, age range and ethnicity.

\section{Conclusion}

This study is the first attempt to apply two sets of quantitative tools to assess the locus of control of African and Caribbean individuals with experience of mental health challenges and services in both generalized and mental health contexts. As active patient engagement is integral for positive health, the results indicate a risk that the sampled population are not likely to engage actively with health care if their perception of externality in LOC remains unchanged. This suggests a need to further explore and address the likely reasons, factors or underlying causes that contributes to the external orientation in the LOC for the clients, improve the level of LOC internality, engagement and ownership of the recovery journeys. Whilst not generalisable to A \& C peoples and all BME populations, it highlights the potential benefits of assessing and applying LOC orientations by professionals and services as a tool towards achieving effective mental health supports. The study also presents a foundational knowledge to achieve more reliable results to further explore the LOC profiles of peoples from BME communities in their experience with mental health services, contribute towards addressing the current disparities in mental health outcomes, and opportunity to evaluate the extent to which this type of exploration could be applied to other health settings.

\section{Declarations}

\subsection{Informed Consent}

The authors declared that signed informed consent was obtained from all participants in this study.

\subsection{Competing Interests}

The authors declared that no conflict of interest exist in this study. 


\subsection{Publisher's Note}

AIJR remains neutral with regard to jurisdictional claims in published maps and institutional affiliations.

\section{How to Cite this Article:}

Joseph, S., \& Keating, F. (2021). Improving Mental Health Outcomes for Black and Minority Ethnic Communities: A Quantitative Study into Perception of Control. Advanced Journal of Social Science, 8(1), 37-53. Retrieved from https://journals.aijr.org/index.php/ajss/article/view/3408

\section{References}

[1] Care Quality Commission. Monitoring the Mental Health Act in 2012/13. 2014. http://www.cqc.org.uk/public/publications/reports/mental-health-act-2012/13. Accessed 23 May 2019.

[2] Bhui K, Stansfeld S, Hull S, Priebe S, Mole F, Feder G. Ethnic variations in pathways to and use of specialist mental health services in the UK: systematic review. British Journal of Psychiatry. 2003; 182:105-116.

[3] Robinson M, Keating F, Robertson S. Ethnicity, Gender and Mental Health. Diversity in Health and Care. 2011; 8: 81-92.

[4] Joseph, S. Exploring the relationship between Locus of Control and the perception of the quality of mental health care experienced by African \& Caribbean service users. 2018. Thesis or dissertation. Available at: pure.royalholloway.ac.uk

[5] Linney, C., Ye, S., Redwood, S. et al. "Crazy person is crazy person. It doesn't differentiate": an exploration into Somali views of mental health and access to healthcare in an established UK Somali community. Int J Equity Health (2020); 19, 190. https://doi.org/10.1186/s12939-020-01295-0

[6] Keating F. Theorising 'race', ethnicity and mental health. In Craig G, Atkin K, Chattoo S, Flynn R, editors. UNDERSTANDING 'RACE' AND ETHNICITY: Theory, history, policy practice. Bristol: Policy Press; 2012. pp. 209-225.

[7] Adebowale L. Independent Commission on Mental Health \& Policing Report. 2013. http://news.bbc.co.uk/2/shared/bsp/hi/pdfs/10_05_13_report.pdf. Accessed 18 July 2018.

[8] Mantovani N, Pizzolati M, Edge D. Exploring the Relationship between Stigma and Help-Seeking for Mental Illness in AfricanDescended Faith Communities in the UK. Health Expectations: An International Journal of Public Participation in Health Care and Health Policy. 2017; 20 (3), 373-384.

[9] Centre for Mental Health. Against the odds: Evaluation of the Mind Birmingham Up My Street programme. 2017. https://www.centreformentalhealth.org.uk/Handlers/Download.ashx?IDMF=14f86686-7882-43cb-b64e-1540f12ab01a. Accessed 15 December 2018.

[10] Keating F, Robertson D, McCulloch A, Francis E. Breaking the circles of fear: a review of the relationship between mental health services and African and Caribbean communities. London: The Sainsbury Centre for Mental Health; 2002.

[11] Annual Report of the Chief Medical Officer 2013, Public Mental Health Priorities: Investing in the Evidence. Department of Health. 2013. https://www.gov.uk/government/uploads/system/uploads/attachment_data/file/413196/CMO_web_doc.pdf. Accessed 20 May 2018

[12] Department of Health. Closing the gap: priorities for essential change in mental health. 2014. https://www.gov.uk/government/uploads/system/uploads/attachment_data/file/281250/Closing_the_gap_V2_-_17_Feb_2014.pdf. Accessed 20 May 2018.

[13] Keating F. 'Racialised Communities, Producing Madness and Dangerousness'. Intersectionalities: A Global Journal of Social Work Analysis, Research, Polity, and Practice; 2016; 5: (3), 1-13

[14] Kotecha N. Black and minority ethnic women. In: Fernando S, Keating F. editors. Mental health in a multi-ethnic society: a multidisciplinary handbook. London: Routledge; 2008. pp. 58-70.

[15] Keating F, Robertson D. 'Fear, Black People and Mental Illness: A Vicious Circle?'. Health \& Social Care in the Community. 2004; $12,(5), 439-447$

[16] Keating F. Social Inequalities and Mental Health: An Integrative Approach. In: Bell A. editor. Beyond the Water Towers: The Unfinished Revolution in Mental Health Services 1985-2005. London: Sainsbury Centre for Mental Health: 2005

[17] Fearon P, Kirkbride J, Morgan C, Dazzan P, Morgan K, Lloyd T, Hutchinson G, Tarrant J, Fung W, Holloway J, Malletti R, Harrison G, Leff J, Jones PB, Murray RM. Incidence of schizophrenia and other psychoses in ethnic minority groups: results from the MRC AESOP Study. Psychological Medicine. 2006; 36: 1541-1550.

[18] Iqbal, Neelam. Minority Mental Health: Intersections between Faith and Ethnicity (January 16, 2021). Available at: SSRN: https://ssrn.com/abstract=3767398 or http://dx.doi.org/10.2139/ssrn.3767398

[19] Smith K, Bhui K, Cipriani A. COVID-19, mental health and ethnic minorities. Evidence-Based Mental Health. 2020 Aug 1; 23(3):8990.

[20] Edge D. Why are you cast down, o my soul? Exploring intersections of ethnicity, gender, depression, spirituality and implications for Black British Caribbean women's mental health. Critical Public Health. 2013; 23 (1) 39-48.

[21] Cheng C, Cheung S, Chio JH, Chan MS. Cultural Meaning of Perceived Control: A Meta-Analysis of Locus of Control and Psychological Symptoms Across 18 Cultural Regions. Psychological Bulletin. 2013; 139 (1) 152-188

[22] Rotter JB. Generalized expectancies for internal versus external control of Reinforcement. Psychological Monographs: General and Applied. 1966: 80, 1-28. doi:10.1037/h0092976.

[23] Bandura A. Social learning theory. Englewood Cliffs, NJ: Prentice Hall. 1977.

[24] Hattrup K, O' Connell M, Labrador J. Incremental validity of locus of control after controlling for cognitive ability and consciousness. Journal of Business and Psychology. 2005; 19, 461-81.

[25] Tigani X, Artemiadis AK, Alexopoulos EC, Chrousos GP, Darviri C. Gender differences in Greek centenarians. A cross-sectional nation-wide study, examining multiple socio-demographic and personality factors and health locus of control. BMC Geriatrics. 2011; $11,(87), 1-8$. 
Stephen Joseph and Frank Keating., Adv. J Social Sci.; Vol. 8, Issue 1, pp: 37-53, 2021

[26] Reknes I, Visockaite G, Liefooghe A, Lovakov A, Einarsen SV. Locus of Control Moderates the Relationship Between Exposure to Bullying Behaviors and Psychological Strain. Front Psychol. 2019; 10, 1323. Source: https://www.ncbi.nlm.nih.gov/pmc/articles/PMC6563764/pdf/fpsyg-10-01323.pdf

[27] Rotter JB. Some problems and misconceptions related to the construct of internal versus external control of reinforcement. Journal of Consulting and Clinical Psychology, 1975; 43, 56-7.

[28] Dijkstraa MTM, Beersma B, Evers A. Reducing conflict-related employee strain: The benefits of an internal locus of control and a problem-solving conflict management strategy. Work and Stress. 2011; 25, 167-84.

[29] Declerck CH, Boone C, De Brabander B. On feeling in control: A biological theory for individual differences in control perception. Brain and Cognition. 2006; 62, 143-176.

[30] Wallston KA, Wallston BS. Health locus of control scales. In H. Lefcourt, editor. Research with the locus of control construct New York: Academic Press. 1981. Vol.1, pp. 189-243.

[31] Wallston KA. Hocus-pocus, the focus isn't strictly on locus: Rotter's social learning theory modified for health. Cognitive Therapy and Research. 1992; 16:183-199.

[32] Seeman M, Seeman TE. Health behaviour and personal autonomy: A longitudinal study of the sense of control in illness. Journal of Health and Social Behaviour. 1983; 24, 144-160.

[33] Marshall G. A multidimensional analysis of internal health locus of control beliefs: Separating the wheat from the chaff. Journal of Personality and Social Psychology. 1991; 61: 483-491.

[34] Abella R, Heslin R. Health, Locus of Control, Values, and the Behavior of Family and Friends: An Integrated Approach to Understanding Preventive Health Behavior. Basic and Applied Social Psychology. 1984; 5, (4): 283-293.

[35] Strickland BR. Internal-external expectancies and health-related behaviors. J. consult. clin, Psychol. 1978; 46: 1192-1211.

[36] Norman P, Bennett P, Smith C, Murphy S. Health Locus of Control and Health Behaviour. Journal of Health Psychology. 1998; 3 : 170-180.

[37] Duffy ME. Determinants of health promotion in midlife women. Nursing Research. 1988; 37: 358-362.

[38] Muhlenkamp AF, Brown NJ, Sands D. Determinants of health promotion activities in nursing clinic clients. Nursing Research. 1985; 34: 327-333.

[39] Steptoe A, Wardle J, Vmck J, Tuomisto M, Holte A, Wichstrom L. Personality and attitudinal correlates of healthy and unhealthy lifestyles in young adults. Psychology and Health. 1994; 9: 331-343.

[40] Wood WD, Letak JK. A mental-health locus of control scale. Person Individ Difference. 1982; 3: 87-88.

[41] Judge TA, Erez A, Bono JE, Thoresen CJ. Are measures of self-esteem, neuroticism, locus of control, and generalized self-efficacy indicators of a common core construct?. Journal of Personality and Social Psychology. 2002; 83: 693-710.

[42] Buhagiar K, Parsonage L, Osborn DPJ. Physical health behaviours and health locus of control in groups with schizophrenia-spectrum disorder and bipolar disorder: a cross-sectional comparative study with groups with non- psychotic mental illness. BMC Psychiatry. 2011; 11 (104): 1-10.

[43] McCabe R, Priebe S. Explanatory models of illness in schizophrenia: comparison of four ethnic groups. British Journal of Psychiatry. 2004; 185: 25-30.

[44] Field A. Comparing Two Means. Discovering Statistics. Video tutorial. 2010. https://www.discoveringstatistics.com/. Accessed 18 October 2019.

[45] UNC Charlotte Department of Psychology To take The Locus of Control Test Click. 2014. (http://www.psych.uncc.edu/pagoolka/LocusofControl-intro.html_Accessed 20 October 2018.

[46] Hill DJ, Bale RM. Development of the Mental Health Locus of Control and Mental Health Locus of Origin Scales. Journal of Personality Assessment. 1980; 44 (2): 148-156.

[47] UNC Charlotte Department of Psychology Locus of Control: based on J.B. Rotter (1966) Generalized expectancies for internal versus external control of reinforcement' Psychological Monographs. 2014: 80 (1), Whole No. $_{609 .}$ http://www.psych.uncc.edu/pagoolka/LC.html__Accessed 20 October 2018.

[48] Halpert R, Hill R. 28 Measures of Locus of Control. 2011. http://teachinternalcontrol.com/uploads/LOC_Measures_1_.pdf. Accessed 25 October 2018.

[49] Wallston KA, Wallston BS, DeVellis R. Development of multidimensional health locus of control (MHLC) scales. Health Education Monographs. 1978; 6:160-170.

[50] Kesavayuth, D.; Poyago-Theotoky, J.; Zikos, V. Locus of control, health and healthcare utilization. Econ. Model. 2020, 86, 227-238

[51] Sigurvinsdotti, R, Thorisdottir, IE, Gylfason, HF. The Impact of COVID-19 on Mental Health: The Role of Locus on Control and Internet Use. Int. J. Environ. Res. Public Health. 2020; 17: 6985; 1-15

Publish your research article in AIJR journals-

$\checkmark \quad$ Online Submission and Tracking

$\checkmark$ Peer-Reviewed

$\checkmark$ Rapid decision

$\checkmark \quad$ Immediate Publication after acceptance

$\checkmark \quad$ Articles freely available online

$\checkmark \quad$ Retain full copyright of your article.

Submit your article at journals.aijr.org
Publish your books with AIJR publisher-

$\checkmark \quad$ Publish with ISBN and DOI.

$\checkmark \quad$ Publish Thesis/Dissertation as Monograph.

$\checkmark$ Publish Book Monograph.

$\checkmark$ Publish Edited Volume/ Book.

$\checkmark$ Publish Conference Proceedings

$\checkmark$ Retain full copyright of your books.

Submit your manuscript at books.aijr.org 